

\section{Effecten van strooisellaagdikte op het gedrag van leghennen}

R.A. van Emous, H. Gunnink, N.W.M. Ogink ${ }^{1}$

${ }^{1}$ Wageningen Livestock Research

Dit onderzoek is uitgevoerd door Wageningen Livestock Research, in opdracht van en gefinancierd door het Ministerie van Economische Zaken, BO-12.02-009

Wageningen Livestock Research

Wageningen, July 2017

Wageningen Livestock Research

Report 1036 
Van Emous, R.A., H. Gunnink, N.W.M. Ogink, 2017. Effecten van strooisellaagdikte op het gedrag van leghennen. Wageningen Livestock Research, Rapport 1036

In dit rapport worden de resultaten gepresenteerd van een experiment naar de effecten van strooisellaagdikte op het gedrag van leghennen. Dit experiment is uitgevoerd in opdracht van het Ministerie van Economische Zaken door Wageningen Livestock Research. Uit dit onderzoek blijkt dat de strooisellaagdikte slechts marginale effecten heeft op het gedrag van leghennen. In zijn totaliteit suggereren de resultaten van dit experiment dat een $2 \mathrm{~cm}$ dikke strooisellaag op gemiddelde basis niet tot minder stofbadgedrag leidt, maar dat er wel sprake is van een ander tijdspatroon waarbij sprake lijkt van uitgesteld stofbadgedrag.

This report presents the results of an experiment into the effects of litter depth on the behaviour of laying hens. This study was conducted by Wageningen Livestock Research and was commissioned by the Ministry of Economic Affairs. This study shows that litter depth has only small effects on behaviour of laying hens. In total the results of this experiment suggests that a $2 \mathrm{~cm}$ litter depth don't lead to less dustbathing behaviour, however, they show a different time patron which indicates postponed dustbathing behaviour.

Dit rapport is gratis te downloaden op https://doi.org/10.18174/420534 of op

www.wur.nl/livestock-research (onder Wageningen Livestock Research publicaties).

(c) 2017 Wageningen Livestock Research

Postbus 338, 6700 AH Wageningen, T 03174839 53, E info.livestockresearch@wur.nl, www. wur.nl/livestock-research. Wageningen Livestock Research is onderdeel van Wageningen University \& Research.

Wageningen Livestock Research aanvaardt geen aansprakelijkheid voor eventuele schade voortvloeiend uit het gebruik van de resultaten van dit onderzoek of de toepassing van de adviezen.

Alle rechten voorbehouden. Niets uit deze uitgave mag worden vermenigvuldigd en/of openbaar gemaakt worden door middel van druk, fotokopie, microfilm of op welke wijze dan ook zonder voorafgaande toestemming van de uitgever of auteur.

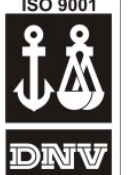

De certificering volgens ISO 9001 door DNV onderstreept ons kwaliteitsniveau. Op als onze onderzoeksopdrachten zijn de Algemene Voorwaarden van de Animal Sciences Group van toepassing. Deze zijn gedeponeerd bij de Arrondissementsrechtbank Zwolle.

Wageningen Livestock Research Report 1036 


\section{Inhoud}

$\begin{array}{ll}\text { Woord vooraf } & 5\end{array}$

$\begin{array}{ll}\text { Samenvatting } & 7\end{array}$

1

$\begin{array}{ll}\text { Inleiding } & 9\end{array}$

1.1 Strooisellaagdikte $\quad 9$

1.2 Strooisellaagdikte en emissie $\quad 9$

$\begin{array}{lll}1.3 & \text { Strooisellaagdikte en gedrag } & 9\end{array}$

2

$\begin{array}{ll}\text { Materiaal en methoden } & 11\end{array}$

2.1 Accommodatie 11

2.2 Proefbehandelingen 11

$\begin{array}{lll}2.3 & \text { Waarnemingen } & 12\end{array}$

2.3.1 Algemeen 12

2.3.2 Gedrag 12

$\begin{array}{lll}2.4 & \text { Statistische analyse } & 13\end{array}$

$3 \quad$ Resultaten en discussie $\quad 14$

$\begin{array}{lll}3.1 & \text { Algemeen } & 14\end{array}$

$\begin{array}{lll}3.2 & \text { Gedragswaarnemingen } & 14\end{array}$

$\begin{array}{llr}4 & \text { Conclusies } & 17\end{array}$

$\begin{array}{lc}\text { Literatuur } & 18\end{array}$

$\begin{array}{llr}\text { Bijlage } 1 & \text { Inrichting stal } & 19\end{array}$

$\begin{array}{lll}\text { Bijlage } 2 \text { Uitvoering testhokken } & 20\end{array}$ 


\section{Woord vooraf}

In het kader van de Programmatische Aanpak Stikstof (PAS) is er behoefte om voer- en managementmaatregelen op te nemen die toegepast zouden kunnen worden om de uitstoot van ammoniak $\left(\mathrm{NH}_{3}\right)$ te verminderen. Een mogelijke oplossing om de emissie van zowel ammoniak als fijnstof te reduceren is het toepassen van een dunnere strooisellaag. Er zijn echter vragen gerezen over het effect van strooisellaagdikte op het gedrag, en dan vooral het stofbadgedrag van leghennen.

In dit rapport worden de resultaten gepresenteerd van een experiment naar de effecten van strooisellaagdikte op het gedrag van leghennen. Deze studie is uitgevoerd door Wageningen UR Livestock Research in opdracht van en gefinancierd door het Ministerie van Economische Zaken.

De wens is dat het hier beschreven onderzoek kan bijdragen aan een gedeeltelijke oplossing van de fijnstofproblematiek in de pluimveehouderij en met name voor de legpluimveehouderij.

Dr.ir. N.W.M. (Nico) Ogink

Projectleider 


\section{Samenvatting}

In het kader van de Programmatische Aanpak Stikstof (PAS) is er behoefte om voer- en managementmaatregelen op te nemen die toegepast zouden kunnen worden om de uitstoot van ammoniak te verminderen. Aanvullende managementmaatregelen betreffen maatregelen die niet gebonden zijn aan de uitvoering van een stalsysteem, zoals een aangepast lichtregime of de inzet van toevoegmiddelen aan mest.

In strooiselstallen voor leghennen komt de meeste ammoniak, geur en fijnstof uit de (strooisel)mest. Een mogelijke oplossing om de emissie van zowel ammoniak als fijnstof te reduceren is het toepassen van een dunnere strooisellaag. Er zijn echter vragen gerezen over het effect van strooisellaagdikte op het gedrag, en dan vooral het stofbadgedrag van leghennen. Daarom is besloten om een onderzoek te starten naar het effect van verschillende strooisellaagdikte op gedrag bij leghennen.

Voor het onderzoek werd gebruik gemaakt van een koppel Brown Nick leghennen van een commercieel pluimveebedrijf. In de strooiselruimte van de stal werden drie testhokken $(1,22 \times 1.22$ $\mathrm{m})$ geïnstalleerd en voorzien van een handmatig voer- en watersysteem. De strooiseldikte per hok ( 2 , 5 of $10 \mathrm{~cm}$ ), werd volgens een random indeling, dagelijks aangepast. De waarnemingen werden verricht gedurende drie opeenvolgende weken met elk vier observatiedagen. Op maandag werden in totaal 24 leghennen gerandomiseerd uit het koppel gevangen en verdeeld over de 3 hokken ( 8 per hok). Per test hok was een camera boven de hennen bevestigd waarbij het gedrag van de dieren werd opgenomen. Naderhand werd dit uitgelezen via de scan-sampling methode waarbij iedere 15 minuten het gedrag van de dieren gescoord werd.

Uit het onderzoek kunnen de volgende conclusies worden getrokken:

- Leghennen die op $2 \mathrm{~cm}$ strooisel werden gehouden vertoonden, t.o.v. dieren op $10 \mathrm{~cm}$ strooisel, meer zitten en foerageren terwijl ze minder liepen.

- Minder eetgedrag rond 13:00 uur werd aangetoond wanneer dieren op 2 of $5 \mathrm{~cm}$ strooisel werden gehouden terwijl dit niet werd gevonden bij de dieren op $10 \mathrm{~cm}$ strooisel.

- Dieren die op $2 \mathrm{~cm}$ strooisel werden gehouden vertoonden een tendens tot uitgesteld stofbadgedrag t.o.v. dieren die op 5 en $10 \mathrm{~cm}$ strooisel werden gehouden.

- Er werden geen verschillen tussen de verschillende strooisellaagdikten gevonden voor het aantal stofbaden, de lengte van het stofbad, het percentage verstoringen tijdens het stofbaden en het starttijdstip van het eerste stofbad.

De overall conclusie is dat strooisellaagdikte slechts kleine verschillen geeft in algemeen gedrag en stofbadgedrag bij leghennen. In zijn totaliteit suggereren de resultaten van dit experiment dat een 2 $\mathrm{cm}$ dikke strooisellaag op gemiddelde basis niet tot minder stofbadgedrag leidt, maar dat er wel sprake is van een ander tijdspatroon waarbij sprake lijkt van uitgesteld stofbadgedrag. 


\subsection{Aanleiding en probleembeschrijving}

In het kader van de Programmatische Aanpak Stikstof (PAS) is er behoefte om voer- en managementmaatregelen op te nemen die toegepast zouden kunnen worden om de uitstoot van ammoniak te verminderen. Aanvullende managementmaatregelen betreffen maatregelen die niet gebonden zijn aan de uitvoering van een stalsysteem, zoals een aangepast lichtregime of de inzet van toevoegmiddelen aan mest.

In strooiselstallen voor leghennen komt de meeste ammoniak, geur en fijnstof uit de (strooisel)mest. Een mogelijke oplossing om de emissie van zowel ammoniak als fijnstof te reduceren is het toepassen van een dunnere strooisellaag. Er zijn echter vragen gerezen over het effect van strooisellaagdikte op het gedrag, en dan vooral het stofbadgedrag van leghennen.

\subsection{Strooisellaagdikte}

Bij de start van een nieuw koppel leghennen wordt op de stalvloer een dun laagje houtkrullen, zand of gehakseld stro verdeeld. In strooiselstallen voor leghennen komt de meeste ammoniak, geur en fijnstof uit de (strooisel)mest (Van Harn et al., 2012). Een mogelijke oplossing om de emissie van zowel ammoniak als fijnstof te reduceren is het toepassen van een dunnere strooisellaag (Van Emous et al., 2009). In de praktijk varieert de laagdikte van het strooisel van minder dan een centimeter (begin legperiode) tot ruim $10 \mathrm{~cm}$ aan het einde van de legperiode (Van Emous et al., 2004).

Pluimveehouders geven tijdens de legperiode de voorkeur aan een dunne strooisellaag (maximaal 1 tot 2 centimeter) doordat een dikkere strooisellaag meer problemen kan geven met grondeieren. Het verzamelen van grondeieren is een arbeidsintensieve activiteit en is daarnaast ongewenst voor de kwaliteit van de eieren. Om de strooisellaag dun te houden wordt tijdens de legperiode regelmatig een gedeelte van het strooisel vanuit de gangpaden verwijderd en op de mestband geschept, waarna het strooisel wordt afgevoerd naar de mestopslag. Veel pluimveehouders met volièrehuisvesting verwijderen tijdens de legperiode twee- tot zesmaal handmatig een gedeelte van het strooisel. Na het verwijderen van het strooisel worden geen verse houtkrullen op de stalvloer aangebracht. De laatste jaren zijn, in het kader van arbeidsvermindering, automatische schuiven ontwikkeld om het strooisel onder de stellingen van volièresystemen frequenter (vaak wekelijks) te verwijderen.

\subsection{Strooisellaagdikte en emissie}

In een studie van Groot Koerkamp en Reitsma (1997), waarbij aan het einde van de legperiode bij leghennen op een volièresysteem de strooisellaag gehalveerd werd (van 9,2 naar 4,7 cm), werd het directe effect van het strooisel verwijderen op de ammoniakemissie op $24 \%$ geschat. Eind 2012 zijn indicatieve metingen gedaan op 2 praktijkbedrijven met volière legkippenbedrijven om het effect van een dunnere strooisellaag op de ammoniakemissie (en fijnstofemissie) te bepalen waarbij de resultaten niet eenduidig waren (Van Emous, pers. med.). Bij het eerste bedrijf werd een reductie op de ammoniak- en fijnstofemissie van respectievelijk $65 \%$ en $37 \%$ gevonden terwijl bij het tweede bedrijf geen verschillen werden aangetroffen. Halverwege 2014 is daarom een project gestart om het effect van strooisellaagdikte op ammoniak en fijnstof op uitgebreidere schaal (vier bedrijven) te meten. De conclusie uit dit onderzoek is dat een dunnere strooisellaag de ammoniakemissie met 25 tot 30\% kan verminderen en de fijnstofemissie met 25 tot 35\% (Mosquera et al., 2016).

\subsection{Strooisellaagdikte en gedrag}

Er zijn echter vragen gerezen over het effect van de strooisellaagdikte op het gedrag, en dan vooral het stofbadgedrag van leghennen. Stofbaden door legkippen is natuurlijk gedrag dat leghennen regelmatig (iedere dag of om de dag) vertonen en wordt meestal uitgevoerd in het midden van de dag (Vestergaard, 1982; Vestergaard et al., 1990). De functie van stofbaden is het verwijderen van oud 
verenvet van veren en huid (Van Liere en Bokma, 1987). Er zijn ook aanwijzingen dat stofbaden helpt bij de verwijdering van ectoparasieten, zoals de vogelmijt (bloedluis) (Simmons, 1964) en de Northern Fowl mite (Van Liere, 1992; Martin en Mullens, 2012; Vezzoli en Mench, 2012).

In de literatuur is nagenoeg geen informatie beschikbaar over de effecten van de dikte van de strooisellaag op het stofbadgedrag. Uit onderzoek met leghennen (Moesta et al., 2008) bleek dat er geen verschil was in stofbadgedrag wanneer leghennen gehouden werden op 2 of $20 \mathrm{~cm}$ dikte strooisellaag. Zij gaven wel aan dat de kwaliteit van het strooisel veel belangrijker is voor de kwaliteit van het stofbadgedrag dan de dikte van de strooisellaag. Bij een dunnere strooisellaag is de kans namelijk groter dat de kwaliteit van het strooisel sneller achteruit gaat door het kleinere bufferende vermogen dan bij een dikkere laag. Vleeskuikenouderdieren die op kooisystemen of grondstal werden gehouden vertoonden geen verschil in lengte van het stofbadgedrag (Van Emous et al., 2008). De dieren op het kooisysteem hadden de beschikking over een matje waar iedere dag een kleine hoeveelheid strooisel werd opgebracht terwijl de dieren in de grondstal de beschikking hadden over een ca. $15 \mathrm{~cm}$ dikke strooisellaag. De dieren in de grondstal vertoonden gemiddeld 19,5 minuut stofbadgedrag terwijl dit bij de kooien met bijna 19 minuten nagenoeg gelijk was.

\subsection{Doel en leeswijzer studie}

In deze studie is beoogd inzicht te verkrijgen over het effect van de strooisellaagdikte op het gedrag van leghennen. Hierbij stonden de volgende onderzoeksvragen centraal:

1. Wat is het effect van strooisellaagdikte op het algemeen gedrag (eten, drinken, staan, zitten, etc.) van leghennen?

2. Wat is het effect van strooisellaagdikte op het stofbadgedrag (lengte stofbad, verstoringen en tijdstip aanvang $1^{\mathrm{e}}$ stofbaden) van leghennen?

3. Wat is het gedragspatroon gedurende de dag van leghennen? In hoofdstuk 2 worden de gebruikte materialen en methoden besproken terwijl in hoofdstuk 3 de resultaten en discussie omtrent de resultaten zijn weergegeven. 


\section{$2 \quad$ Materiaal en methoden}

\section{$2.1 \quad$ Accommodatie en dieren}

Voor het onderzoek werd gebruik gemaakt van een koppel Brown Nick leghennen van een commercieel pluimveebedrijf (Westeneng, Lunteren, Nederland). De dieren (totaal 47.800 stuks) werden gehouden in een stal met volièrehuisvesting (Farmer Automatic, Duitsland). De stal was verdeeld in twee etages met elk 23.900 leghennen per verdieping met een netto vloeroppervlakte per etage van $93 \times 21.5 \mathrm{~m}$ (lengte $\times$ breedte). Het volièresysteem bestond uit geïntegreerde legnesten, sleepkettingen, drinknippels en zitstokken (inrichting stal: Bijlage 1). De mest werd tweemaal per dag via mestbanden uit de stal verwijderd en naar een droogtunnel getransporteerd. Bij de start van de legperiode werd een dun laagje $(1 \mathrm{~cm})$ gehakseld stro over de stalvloer verspreid. De stal werd verlicht met daglicht ( $3 \%$ van de staloppervlakte) in de zijwand van de stal en kunstlicht (hoogfrequente TL buizen aan het plafond). De daglengte was 15 uur licht waarbij het licht tussen 04:00 en 19:00 uur was ingeschakeld. De verse lucht kwam de stal binnen via 44 inlaatventielen (40 $x 90 \mathrm{~cm})$ per verdieping in de zijwand en de stallucht werd afgevoerd via een ventilator $\left(1,26 \mathrm{~m}^{3} / \mathrm{u}\right.$ per hen) in de zijwand naar de droogtunnel (halverwege de stal) en via 4 ventilatoren ( $6.69 \mathrm{~m}^{3} / \mathrm{u}$ per hen) in de eindgevel. De inlaatventielen en de ventilatoren werden aangestuurd door temperatuurvoelers die verbonden waren met een klimaatcomputer. De streeftemperatuur stond gedurende het onderzoek op $19,5^{\circ} \mathrm{C}$ ingesteld.

\subsection{Proefbehandelingen}

Voor het onderzoek werden drie testhokken van 1,22 × 1,22 × 2,90 m (lengte $\times$ breedte $\times$ hoogte) gemaakt in de strooiselruimte aan de rechterzijde van de stal (Bijlage 2). Alle hokken waren uitgerust met een handmatig te vullen voerpan en ronddrinker (Figuur 1). Verder was er een zitstok (lengte 1,22 op 1,22 m hoogte) aanwezig. In verband met de ruimte waren er geen legnesten en roosters in de testhokken geplaatst. Het strooisel van de volièrestal werd gebruikt om de verschillende strooisellaagdikten $(2,5$ of $10 \mathrm{~cm})$ in de testhokken te creëren. De strooiseldikte per test hok, werd volgens een random indeling, dagelijks aangepast. De waarnemingen werden verricht gedurende drie opeenvolgende weken (week 44, 45 en 46 in 2015) met elk vier opeenvolgende observatiedagen. Op elke maandag van een observatieweek werden 24 leghennen uit het koppel random verzameld en verdeeld over de 3 hokken ( 8 per hok; $1.861 \mathrm{~cm}^{2} /$ leghen). Hierdoor hadden de hennen één dag de tijd om te wennen aan de nieuwe omgeving. De gedragsobservaties werden verricht op de vier opeenvolgende dagen (dinsdag tot en met vrijdag. Op alle ochtenden van de observatiedagen werden de hennen voor 08:00 uur gevangen en gedurende circa één uur in kippenkratten geplaatst om de testhokken in orde te maken. Dit betekende: eieren rapen, de strooisellaag op de gewenste dikte brengen, apparatuur controleren en het voer- en watersysteem vullen. Na deze voorbereidingen werden de leghennen iedere dag rond 08:45 random verdeeld over de testhokken. De gedragsobservaties werden uitgevoerd tussen 09:00 en 16:00 uur gedurende drie opeenvolgende weken met elk vier observatie dagen (in totaal 12 observatie dagen per strooiseldikte). Aan het einde van de observatieweek (vrijdag namiddag) werden de leghennen losgelaten in het koppel. 


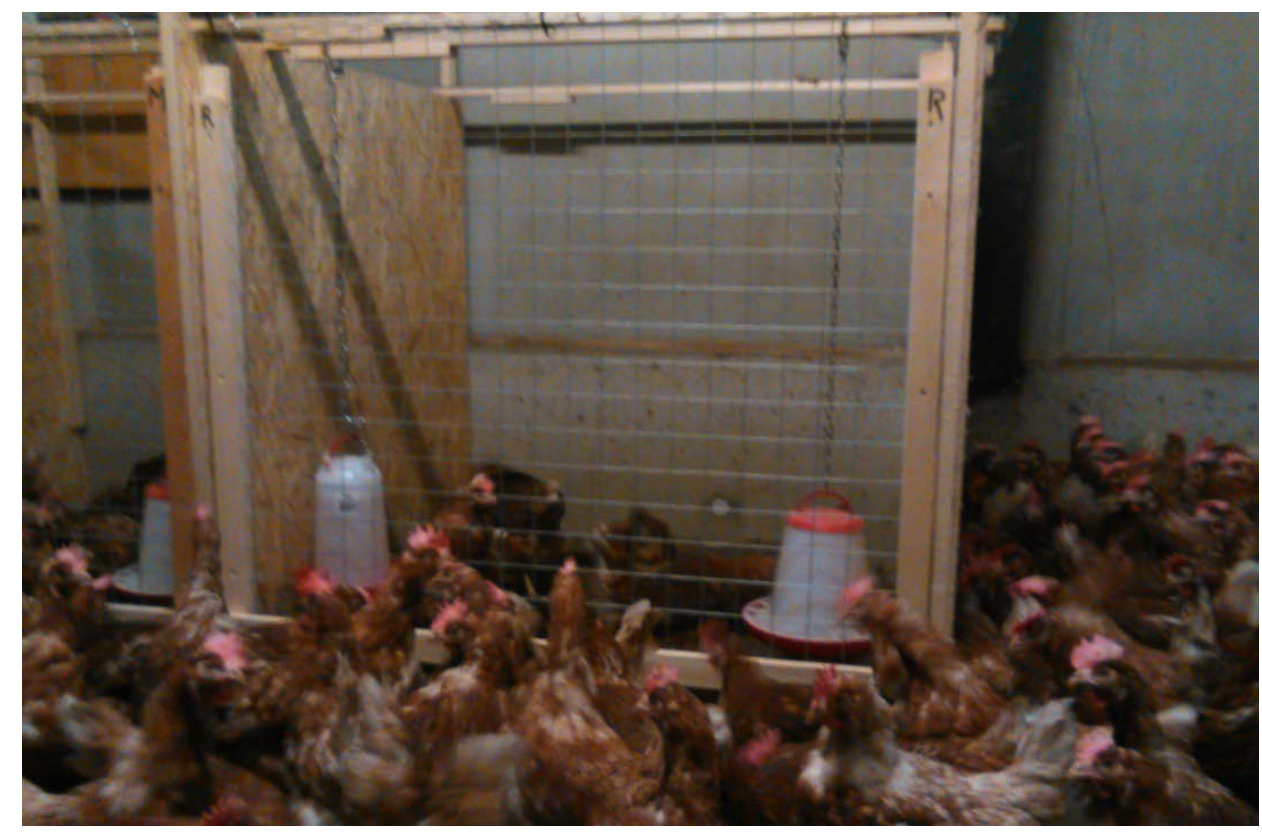

Figuur 1 Overzicht van een test hok.

\subsection{Waarnemingen}

\subsubsection{Algemeen}

Voor aanvang en aan het einde van de gedragsobservaties werd een monster per testhok van het strooisel verzameld om het drogestofgehalte te bepalen. Op de dagen van de gedragsobservaties (dinsdag tot en met vrijdag) werd de minimum en maximum temperatuur van de stal vanaf de klimaatcomputer uitgelezen. De verlichtingssterkte (lux) in alle testhokken werd op ooghoogte van de dieren (ca. $25 \mathrm{~cm}$ hoogte) op de gedragsobservatie dagen gemeten.

\subsubsection{Gedrag}

Per test hok was een camera circa 2 meter boven de hennen bevestigd waarbij het gedrag van de dieren werd opgenomen en digitaal opgeslagen. Naderhand werd dit uitgelezen via de scan-sampling methode waarbij iedere 15 minuten het gedrag van de dieren gescoord werd. Daarbij werd steeds het aantal dieren geteld wat op dat moment bepaald gedrag (Tabel 1) vertoonde.

Tabel 1 Ethogram gedragswaarnemingen (naar De Jong et al., 2005).

\begin{tabular}{ll} 
Gedrag & Omschrijving \\
Eten & Pikken naar voer in de voerpan \\
\hline Drinken & Pikken naar water in de ronddrinker \\
\hline Staan & Staan zonder uitvoeren van ander gedrag (zoals comfort, foerageren, pikken, etc.) \\
\hline Zitten & Zitten zonder uitvoeren van ander gedrag (zoals comfort, foerageren, pikken, etc.) \\
\hline Lopen & Lopen of rennen zonder uitvoeren van ander gedrag (zoals comfort, foerageren, pikken, etc.) \\
\hline Foerageren & Pikken en scharrelen in het strooisel \\
\hline Comfort & Verzorgingsgedrag zoals poetsen, rekken, strekken, vleugelslaan \\
\hline Stofbaden & Stofbadgedrag in het strooisel \\
\hline Object pikken & Pikken in/naar leeg voer- en/of watersysteem en delen van inrichting of wand \\
\hline Zitstok & Pikken naar andere dieren (kop of lichaam) \\
\hline
\end{tabular}

Gedurende het uitlezen van de video-opnamen werd de start en het einde van het stofbadgedrag genoteerd. Voor de start van het stofbadgedrag werd het moment gekozen waarbij het dier het zogenaamde in- of vleugelschudden in het strooisel vertoont (Figuur 2; Van Liere, 1991). Hierbij maakt een dier een serie snel opeenvolgende krabbewegingen met één poot terwijl het dier de veren opzet en de vleugel naar buiten houdt. Vervolgens maakt het dier een snelle serie krabbewegingen 
met de andere poot (Van Liere, 1991). Het stofbadgedrag eindigde wanneer het dier het zogenaamde uitschudden vertoonde. Hierbij staat het dier op, zet de veren op en schudt het lichaam een of meerdere malen krachtig waarbij het strooisel verwijderd wordt. Niet bij al het waargenomen stofbadgedrag werd dit uitschudden gezien. Voor die stofbaden werd het moment gekozen wanneer het dier opstond. Tijdens het uitlezen van het stofbadgedrag werden ook de verstoringen van het stofbadgedrag gescoord.

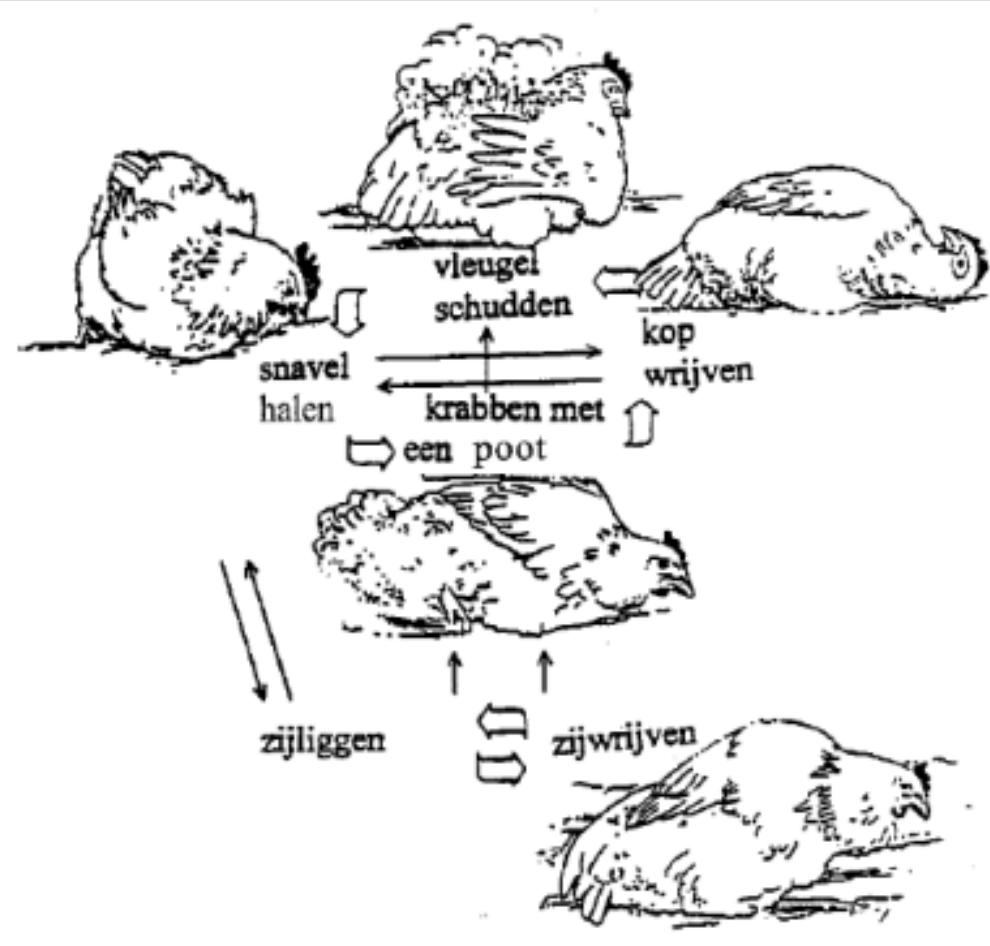

Figuur 2 Elementen van het stofbadgedrag (Van Liere, 1991)

\subsection{Statistische analyse}

De gedragswaarnemingen zijn geanalyseerd met de REML procedure in het statistische programma Genstat (Genstat 17.1 Committee, 2014) waarbij tijdstip van de dag werd meegenomen in het model. De gedragswaarnemingen over de verschillende weken zijn geanalyseerd als herhaalde waarnemingen. De waarnemingen aan het stofbadgedrag (aantal, tijdsduur, tijdstip) zijn geanalyseerd met de variantieanalyse (ANOVA) waarbij week en hok werden meegenomen als blok effect.

Verschillen werden significant beschouwd bij een $\mathrm{P}$-waarde $<0,05$. Een tendens tot een verschil werd beschouwd bij een $\mathrm{P}$-waarde $0,05<\mathrm{P}<0,10$. 


\section{Resultaten en discussie}

\subsection{Algemeen}

Het drogestofgehalte van het strooisel was voor en na aanvang van de gedragswaarnemingen respectievelijk 77,2 en 79,7\% (gemiddeld 78,5\%). De gemiddelde lichtsterkte over de waarnemingsdagen was 28 lux (range: $17-44$ lux) terwijl de gemiddelde temperatuur $22,3^{\circ} \mathrm{C}$ (range: $\left.19,9-24,7^{\circ} \mathrm{C}\right)$ was.

\subsection{Gedragswaarnemingen}

Zitten, lopen, foerageren en eten De resultaten van de gedragswaarnemingen zijn in Tabel 2 weergegeven. Uit de tabel blijkt dat de dieren die bij de $2 \mathrm{~cm}$ strooisellaag werden gehouden, ten opzichte van de $10 \mathrm{~cm}$, meer tijd besteedden aan zitten $(P=0,025)$ en foerageren $(P=0,028)$ en minder aan lopen $(P=0,041)$. De dieren die bij de $5 \mathrm{~cm}$ strooisellaag werden gehouden lagen qua eerder genoemde gedragingen zitten er meestal tussenin. Er werd een interactie gevonden tussen strooisellaagdikte en tijdstip van de dag voor de gedraging eten $(P=0,027)$ en is weergegeven in Figuur 3. Uit de figuur blijkt dat om 13:00 uur de dieren die op de $10 \mathrm{~cm}$ strooisellaag werden gehouden t.o.v. de dieren op de 2 en $5 \mathrm{~cm}$ strooisellaag een hoger percentage aantal aten terwijl bij de andere tijdstippen er geen verschil was. De reden voor dit effect is niet goed duidelijk.

\section{Stofbaden}

Er werd geen statistisch significant verschil gevonden in stofbadgedrag $(P=0,11)$ tussen de verschillende strooisellaagdikten, wanneer beschouwd als hoofdeffect. Er was echter wel een tendens tot een interactie tussen strooisellaagdikte en tijdstip van de dag waarop het stofbaden plaatsvond (Figuur 4). Uit de figuur blijkt dat, binnen de $2 \mathrm{~cm}$ strooisellaagdikte groep, op de tijdstippen 10:00 en 11:00 uur het laagste percentage dieren aan het stofbaden waren terwijl dit voor de 5 en $10 \mathrm{~cm}$ groepen piekmomenten waren waarna het gedurende de dag langzaam afnam. Vanaf 13:00 uur waren er geen verschillen tussen de verschillende dikten strooisellaag. Uit de figuur blijkt verder dat de dieren die op de $2 \mathrm{~cm}$ strooisellaag gehouden werden later begonnen met stofbadgedrag en piekten rond 12:00 tot 13:00 uur terwijl de dieren die op de 5 en $10 \mathrm{~cm}$ strooisellaag werden gehouden meer stofbadgedrag vertoonden om 10:00 en 11:00 uur waarna het gedurende de dag langzaam afnam. Deze tendens blijkt ook duidelijk uit Tabel 3 waar de gemiddelde starttijd van het stofbad is aangegeven. De dieren die bij de $2 \mathrm{~cm}$ strooisellaag werden gehouden startten gemiddeld om 12:26 uur met het stofbadgedrag terwijl dit bij de dieren die bij de 5 en $10 \mathrm{~cm}$ strooisellaag werden gehouden 11:08 en 11:38 uur bedroeg. In zijn totaliteit suggereren de resultaten van dit experiment dat een $2 \mathrm{~cm}$ dikke strooisellaag op gemiddelde basis niet tot minder stofbadgedrag leidt, maar dat er wel sprake is van een ander tijdspatroon waarbij sprake lijkt van uitgesteld stofbadgedrag.

Voor staan, objectpikken, kip pikken en zitten op de zitstok werden geen verschillen gevonden in het percentage dieren dat dit gedrag uitoefende gedurende de dag (Tabel 2). Voor de andere gedragingen werden wel patronen in het gemiddelde gedrag waargenomen. Het percentage dieren dat:

- eet- en drinkgedrag vertoonden nam licht toe,

- foerageergedrag vertoonde nam flink toe,

- zit-, stofbad- en comfortgedrag vertoonden nam flink af. 
Tabel 2 Effect van strooiseldikte en tijdstip van de dag op het vertonen van verschillende gedragingen ( $\%$ dieren dat bepaald gedrag vertoonde).

\begin{tabular}{|c|c|c|c|c|c|c|c|c|c|c|c|}
\hline & Eten ${ }^{1}$ & Drink $^{1}$ & Staan ${ }^{1}$ & Zit $^{1}$ & Lopen $^{1}$ & Foerag $^{1}$ & Comf ${ }^{1}$ & Stofbad $^{1}$ & Object ${ }^{1}$ & Kip ${ }^{1}$ & Zitstok ${ }^{1}$ \\
\hline \multicolumn{12}{|l|}{ Strooisel } \\
\hline $2 \mathrm{~cm}$ & 25,0 & 5,2 & 7,2 & $14,4^{x}$ & $10,0^{y}$ & $22,7^{x}$ & 9,6 & 2,1 & 1,7 & 1,0 & 1,2 \\
\hline $5 \mathrm{~cm}$ & 25,7 & 4,8 & 9,2 & $10,8^{y}$ & $11,3^{x y}$ & $20,9^{x y}$ & 10,6 & 2,9 & 2,3 & 0,9 & 0,6 \\
\hline $10 \mathrm{~cm}$ & 24,8 & 5,7 & 9,3 & $10,6^{y}$ & $12,8^{x}$ & $18,0^{y}$ & 11,3 & 2,7 & 2,1 & 1,6 & 1,2 \\
\hline SEM & 1,9 & 0,5 & 1,1 & 1,1 & 0,9 & 1,7 & 1,0 & 0,5 & 0,4 & 0,3 & 0,4 \\
\hline \multicolumn{12}{|l|}{ Tijdstip } \\
\hline $10: 00$ & $22,1^{b}$ & $4,5^{a b c}$ & 7,8 & $16,9^{a}$ & 11,8 & $17,6^{c}$ & $10,4^{\mathrm{abc}}$ & $4,9^{a}$ & 1,3 & 1,0 & 1,8 \\
\hline $11: 00$ & $25,5^{\mathrm{ab}}$ & $4,7^{b c}$ & 7,6 & $13,8^{b}$ & 10,5 & $17,6^{c}$ & $13,0^{\mathrm{a}}$ & $3,7^{\mathrm{ab}}$ & 2,0 & 0,5 & 1,1 \\
\hline $12: 00$ & $26,6^{\mathrm{ab}}$ & $3,4^{c}$ & 8,9 & $12,5^{b c}$ & 12,2 & $18,5^{c}$ & $11,7^{\mathrm{ab}}$ & $2,4^{b c}$ & 2,2 & 1,2 & 0,4 \\
\hline $13: 00$ & $23,2^{b}$ & $5,1^{a b c}$ & 7,7 & $12,0^{\mathrm{bc}}$ & 11,9 & $20,1^{b c}$ & $12,5^{\mathrm{ab}}$ & $3,2^{\mathrm{ab}}$ & 1,8 & 1,4 & 1,1 \\
\hline $14: 00$ & $25,3^{\mathrm{ab}}$ & $6,9^{a}$ & 10,0 & $12,2^{\mathrm{bc}}$ & 10,2 & $19,0^{c}$ & $10,1^{\mathrm{abc}}$ & $1,8^{b c}$ & 2,1 & 1,5 & 0,9 \\
\hline $15: 00$ & $28,3^{a}$ & $6,0^{a b}$ & 8,0 & $8,7^{\mathrm{cd}}$ & 10,3 & $23,2^{b}$ & $8,9^{b c}$ & $1,6^{b c}$ & 2,8 & 1,1 & 1,1 \\
\hline $16: 00$ & $25,1^{\mathrm{ab}}$ & $6,0^{\mathrm{ab}}$ & 9,6 & $7,5^{d}$ & 12,4 & $28,0^{a}$ & $6,9^{c}$ & $0,4^{c}$ & 2,0 & 1,3 & 0,7 \\
\hline SEM & 2,1 & 1,0 & 1,4 & 1,3 & 1,4 & 1,9 & 1,5 & 1,0 & 0,6 & 0,4 & 0,7 \\
\hline \multicolumn{12}{|l|}{ P-waarde } \\
\hline Strooisel & 0,89 & 0,62 & 0,36 & 0,025 & 0,041 & 0,028 & 0,21 & 0,11 & 0,36 & 0,10 & 0,66 \\
\hline Tijdstip & 0,003 & 0,028 & 0,44 & $<0,001$ & 0,27 & $<0,001$ & $<0,001$ & $<0,001$ & 0,30 & 0,088 & 0,19 \\
\hline Str $*$ Tijd & 0,027 & 0,48 & 0,51 & 0,63 & 0,14 & 0,96 & 0,86 & 0,070 & 0,43 & 0,82 & 0,21 \\
\hline \multicolumn{12}{|c|}{$\begin{array}{l}\text { Eten }=\text { eten uit de voerpan, drink }=\text { drinken uit de ronddrinker, staan }=\text { staan zonder ander gedrag, zit }=\text { zitten zonder ander gedrag, lopen }= \\
\text { lopen zonder ander gedrag, comf }=\text { verzorgingsgedrag, stofbad }=\text { stofbadgedrag, object }=\text { pikken naar objecten, kip }=\text { pikken naar andere } \\
\text { kippen, zitstok = zitten op zitstok }\end{array}$} \\
\hline
\end{tabular}

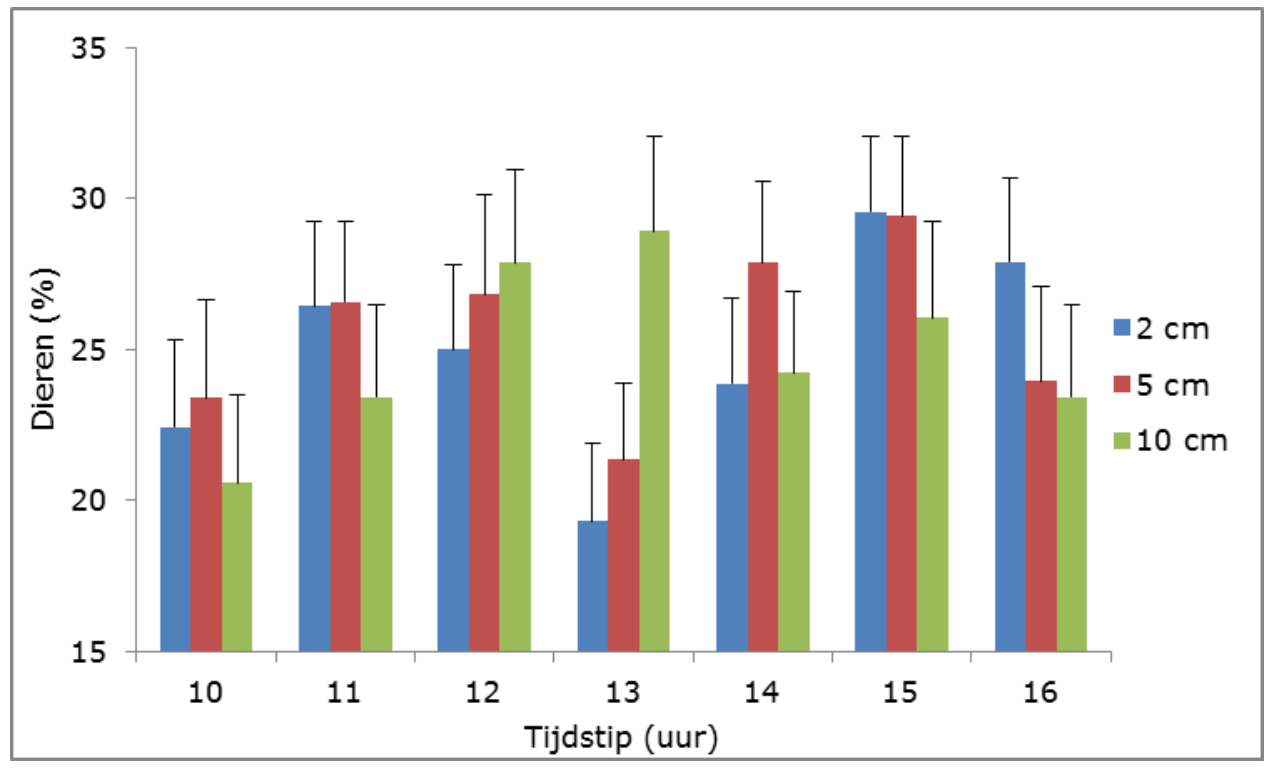

Figuur 3 Effect van strooiseldikte $(2,5$ of $10 \mathrm{~cm}$ ) en tijdstip van de dag (10:00 tot 16:00 uur) op het percentage dieren (gemiddelde en SEM) dat eetgedrag vertoont. 


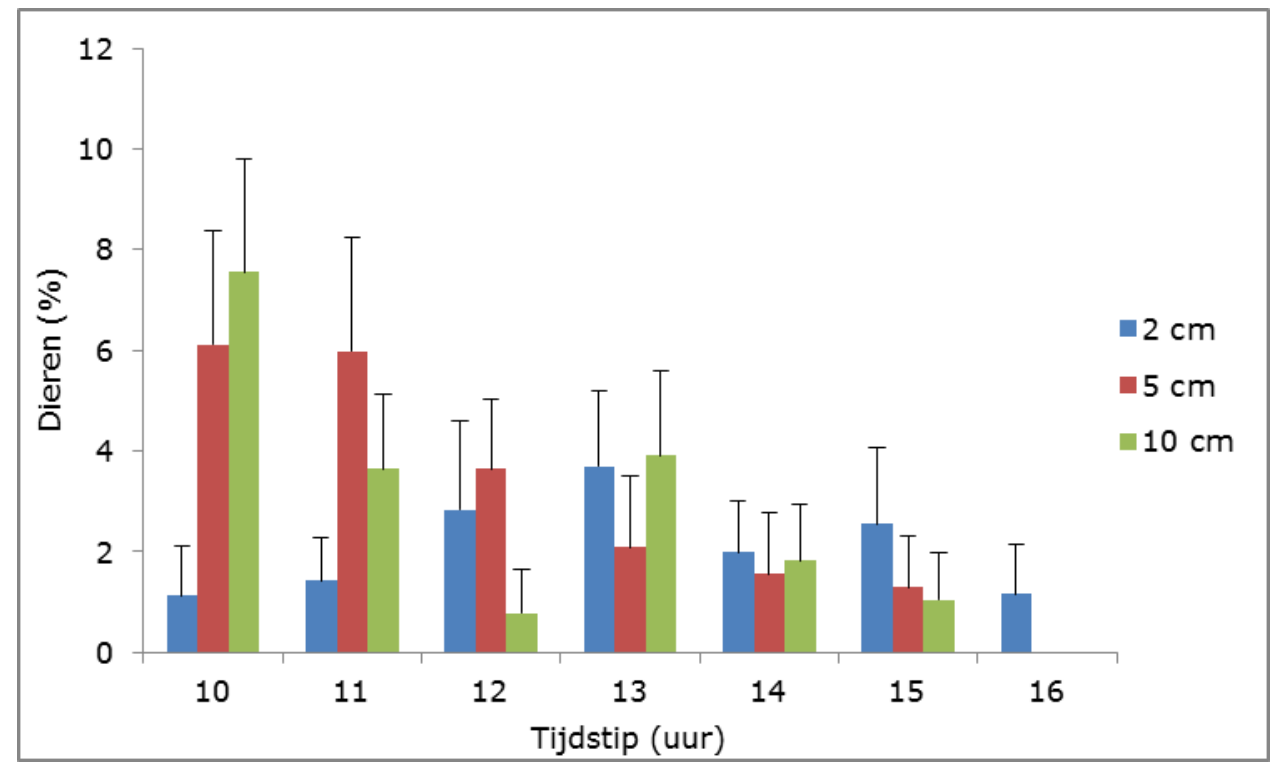

Figuur 4 Effect van strooiseldikte $(2,5$ of $10 \mathrm{~cm}$ ) en tijdstip van de dag (10:00 tot 16:00 uur) op het percentage dieren (gemiddelde en SEM) dat stofbadgedrag vertoont.

Er werden geen effecten waargenomen van de strooisellaagdikte op het aantal stofbaden, lengte van het stofbadgedrag, percentage verstoringen, starttijdstip van het eerste stofbad in de testhokken en gemiddelde starttijd van de stofbaden (Tabel 3). Het ontbreken van een effect van de lengte van het stofbad komt overeen met het onderzoek van Moesta et al. (2008). Moesta et al. (2008) onderzochten het stofbadgedrag van hennen in kooien. Daartoe werden steeds 4 hennen in een kooi geplaatst, met toegang tot een strooiselbak met een ondiepe laag strooisel $(2 \mathrm{~cm}$ ) of een diepe laag strooisel (20 $\mathrm{cm}$ ). Uit het onderzoek kwam naar voren dat de diepte van het strooisel geen aantoonbaar effect had. De kwaliteit van het strooisel gaf echter werd wel een verschil op stofbadgedrag. Bij slechter strooisel werd minder stofbadgedrag waargenomen.

In het huidige experiment werd een tendens gevonden tot een latere gemiddelde starttijdstip (11:14) de stofbaden bij de dieren die op de $2 \mathrm{~cm}$ t.o.v. de dieren die op de $5 \mathrm{~cm}$ strooisellaag (09:58) werden gehouden. De dieren die op de $10 \mathrm{~cm}$ strooisellaag werden gehouden zaten er tussenin (10:26). In de regel wordt er van uitgegaan dat het stofbadgedrag op het midden van de dag plaats vind. Bij dit bedrijf werd het licht om 04:00 in- en om 19:00 uur uitgeschakeld. Dit betekent dat we het stofbadgedrag rond 11:30 uur konden verwachtten. Dit komt goed overeen met de start van het stofbadgedrag bij de dieren die bij de strooisellaagdikte van $2 \mathrm{~cm}$ werden gehouden. De andere hokken waren echter opvallen eerder.

Tabel 3 Effect van strooiseldikte op aantal stofbaden, lengte stofbadgedrag, verstoringen en tijdstip eerste stofbad.

\begin{tabular}{|c|c|c|c|c|c|}
\hline & Stofbaden (\#) & $\begin{array}{l}\text { Lengte stofbad } \\
\qquad(\mathrm{min})\end{array}$ & Verstoringen (\%) & $\begin{array}{l}\text { Tijdstip } 1^{\mathrm{e}} \text { stofbad } \\
\text { (tijdstip dag) }\end{array}$ & $\begin{array}{c}\text { Gemiddelde tijd } \\
\text { stofbad (tijdstip } \\
\text { dag) }\end{array}$ \\
\hline $2 \mathrm{~cm}$ & 4,5 & $20: 23$ & 15,3 & $11: 13: 55$ & $12: 26: 21^{(a)}$ \\
\hline $5 \mathrm{~cm}$ & 5,7 & 20:05 & 14,1 & 09:57: 36 & $11: 07: 44^{(b)}$ \\
\hline P-waarde & 0,19 & 0,30 & 0,93 & 0,14 & 0,075 \\
\hline
\end{tabular}

(a..d) Verschillende letters in dezelfde kolom tussen haakjes geven een tendens tot een verschil aan $(0,05<P<0,10)$ 


\section{$4 \quad$ Conclusies}

Uit het onderzoek kunnen de volgende conclusies worden getrokken:

- Leghennen die op $2 \mathrm{~cm}$ strooisel werden gehouden vertoonden, t.o.v. dieren op $10 \mathrm{~cm}$ strooisel, meer zitten en foerageren terwijl ze minder liepen.

- Minder eetgedrag rond 13:00 uur werd aangetoond wanneer dieren op 2 of $5 \mathrm{~cm}$ strooisel werden gehouden terwijl dit niet werd gevonden bij de dieren op $10 \mathrm{~cm}$ strooisel.

- Dieren die op $2 \mathrm{~cm}$ strooisel werden gehouden vertoonden een tendens tot uitgesteld stofbadgedrag t.o.v. dieren die op 5 en $10 \mathrm{~cm}$ strooisel werden gehouden.

- Er werden geen verschillen tussen de verschillende strooisellaagdikten gevonden voor het aantal stofbaden, de lengte van het stofbad, het percentage verstoringen tijdens het stofbaden en het starttijdstip van het eerste stofbad.

De overall conclusie is dat strooisellaagdikte slechts kleine verschillen geeft in algemeen gedrag en stofbadgedrag bij leghennen. In zijn totaliteit suggereren de resultaten van dit experiment dat een 2 $\mathrm{cm}$ dikke strooisellaag op gemiddelde basis niet tot minder stofbadgedrag leidt, maar dat er wel sprake is van een ander tijdspatroon waarbij sprake lijkt van uitgesteld stofbadgedrag. 


\section{Literatuur}

Groot Koerkamp, P. W. G. en B. Reitsma. 1997. De ammoniakemissie uit een volièrestal voor leghennen met het etagesysteem. Rapport 97-05. DLO-IMAG, Wageningen.

Martin, C. D., and B. A. Mullens. 2012. Housing and dustbathing effects on northern fowl mites (Ornithonyssus sylviarum) and chicken body lice (Menacanthus stramineus) on hens. Medical and veterinary entomology, 26, 323-333.

Moesta, A., U. Knierim, A. Briese, and J. Hartung. 2008. The effect of litter condition and depth on the suitability of wood shavings for dustbathing behaviour. Applied Animal Behaviour Science, 115, 160-170.

Mosquera, J., R. van Emous, T. van Hattem, G. Nijeboer, J.M.G. Hol. H.J. van Dooren and N.W.M. Ogink. Effect van strooiselverwijdering bij leghennen in volièrehuisvesting op de emissie van ammoniak, geur, broeikasgassen en fijnstof. Livestock Research Rapport 995. Wageningen UR (University \& Research centre) Livestock Research, Wageningen.

Simmons, K.E.L., 1964. Feather maintenance. In: A.L. Thompson. A New Dictionary of Birds. pag. 278-286. New York: McGraw-Hill.

Van Emous, R. A., H. H. Ellen en Th. G. C. M. Fiks-van Niekerk. 2004. Inrichting, verlichting, ammoniak en stof bij volièreonderzoek (2e proef). PraktijkRapport Pluimvee 14. Animal Sciences Group, Divisie Veehouderij, Lelystad.

Van Emous, R. A., I. C. de Jong, H. Gunnink en M. Wolthuis-Fillerup. 2008. Scharrel- en stofbadgedrag vleeskuikenouderdieren in het Veranda systeem. Vertrouwelijk rapport 118. Animal Sciences Group van Wageningen UR, Lelystad.

Van Emous, R. A., J. van Harn en A. J. A. Aarnink. 2009. Maatregelen ter vermindering van fijnstofemissie uit de pluimveehouderij: effecten van strooisellaagdikte. Rapport 254. Animal Sciences Group, Divisie Veehouderij, Lelystad.

Van Harn, J., H. H. Ellen, T. Veldkamp en A. J. A. Aarnink. 2012. Effect van huisvestings- en managementmaatregelen op de ammoniakemissie bij leghennen, vleeskuikens, kalkoenen en eenden. Rapport 560. Wageningen UR Livestock Research, Lelystad.

Van Liere, D.W. 1991. Function and Organization of Dustbathing in Laying Hens. PhD, Wageningen Agricultural University, Wageningen.

Van Liere, D. W. 1992. The significance of fowls' bathing in dust. Animal Welfare, 1, 187-202.

Vestergaard, K. 1982. Dust-bathing in the domestic fowl - diurnal rhythm and dust deprivation. Applied Animal Ethology, 8, 487-495.

Vestergaard, K., J. A. Hogan, and J. P. Kruijt. 1990. The Development of a Behavior System: Dustbathing in the Burmese Red Junglefowl I. The Influence of the Rearing Environment on the Organization of Dustbathing. Behaviour, 112, 99-116.

Vezzoli, G., and J. Mench. 2012. Does dustbathing behavior by laying hens reduce Northern Fowl mite populations? Proceedings of the $46^{\text {th }}$ Congress of the ISAE, Vienna, Austria, pp. 169. 


\section{Bijlage 1 Inrichting stal}

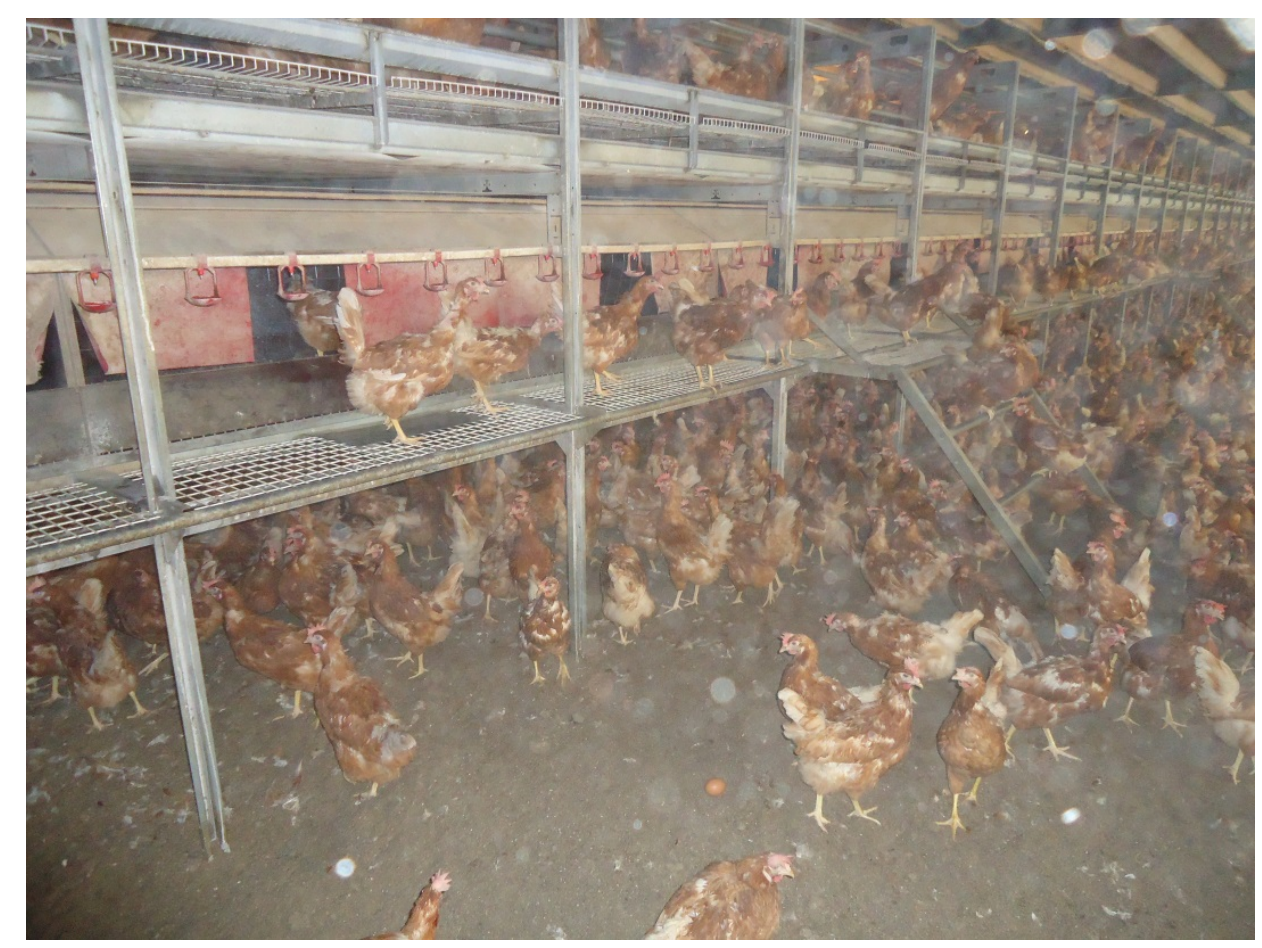

Foto 1: Overzicht van het volièresysteem met strooiselruimte, legnesten en drinknippellijn.

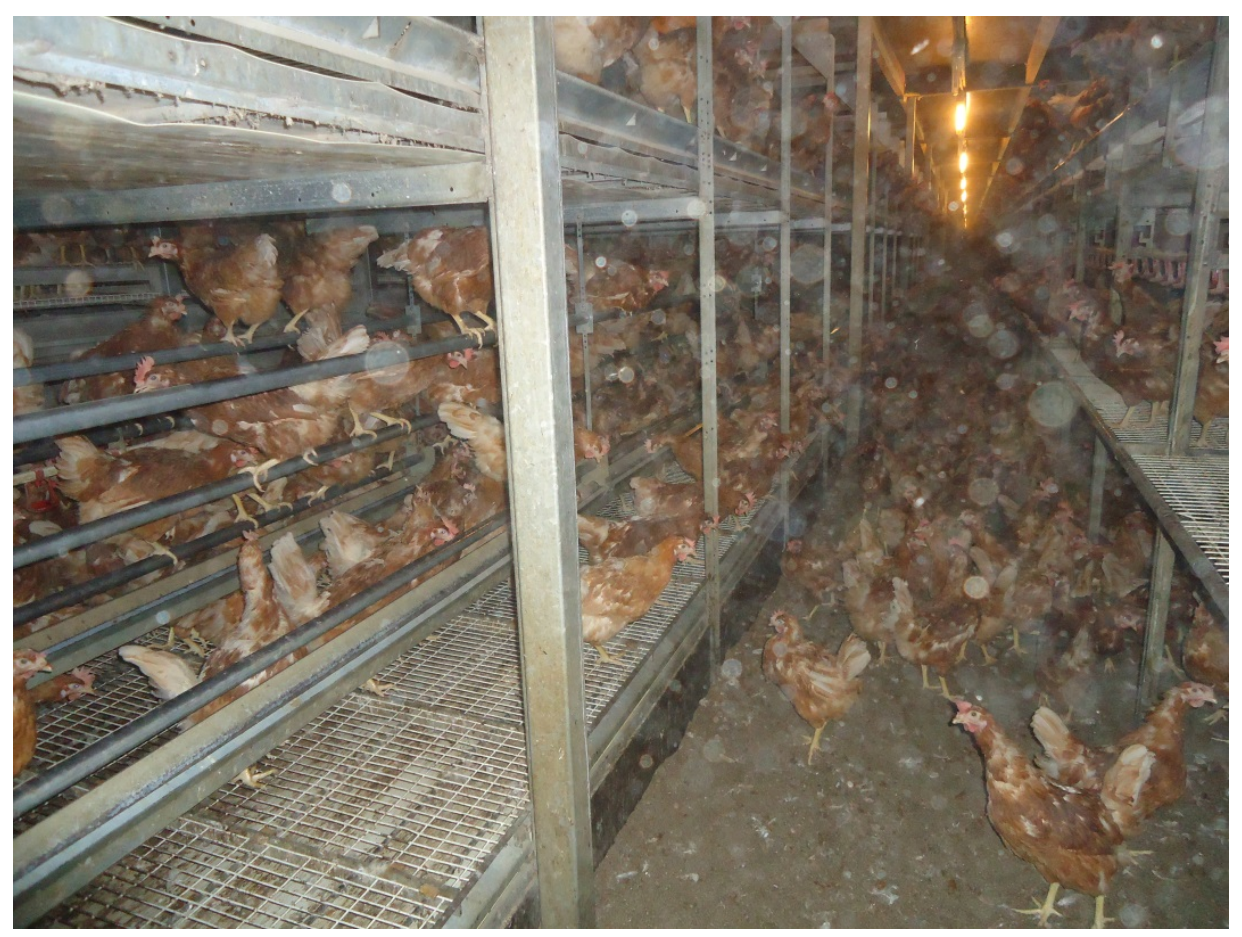

Foto 2: Overzicht van het volièresysteem met stellingen, voersysteem, zitstokken en verlichting. 


\section{Bijlage 2 Uitvoering testhokken}

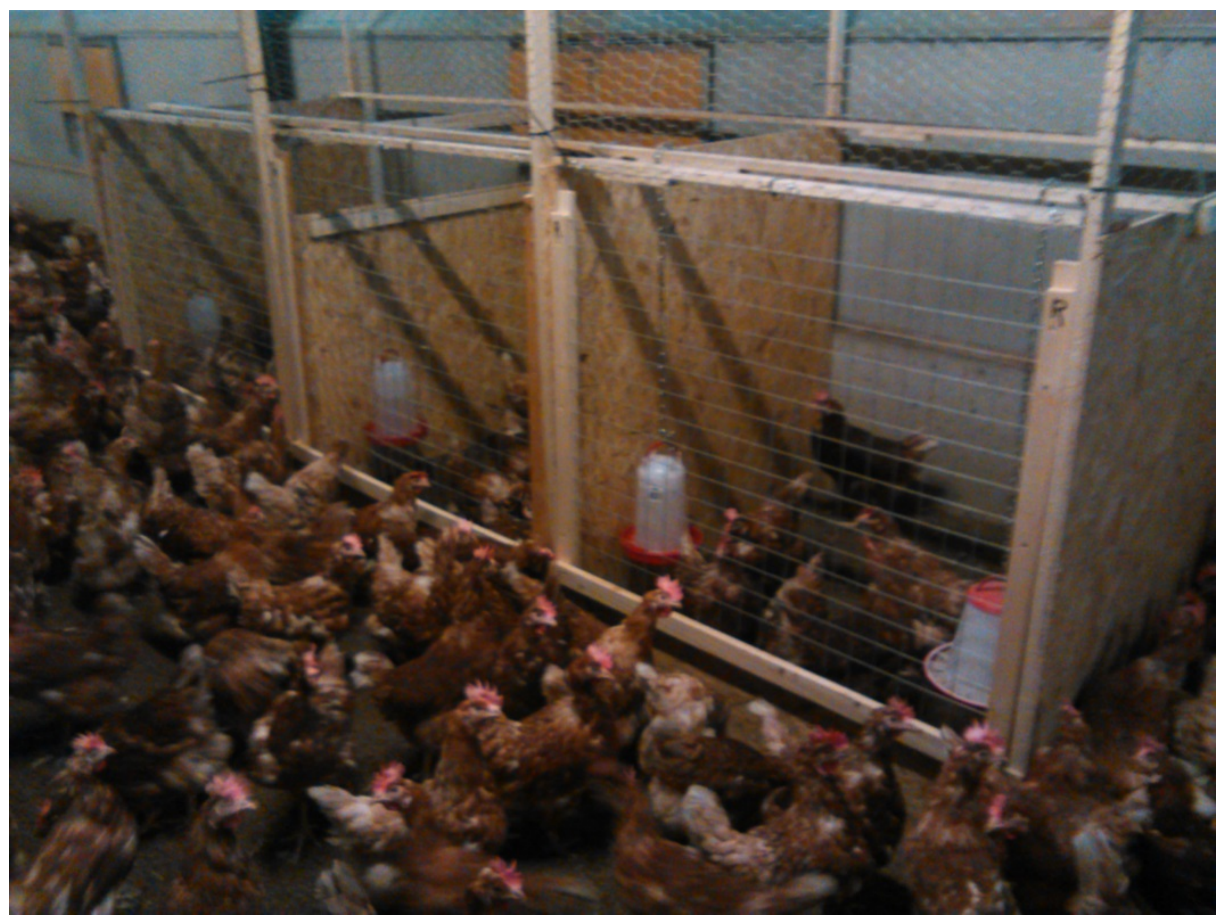

Foto 1: Overzicht van de testhokken in de strooiselruimte (rechterzijde stal) met voerpan (rechts) en ronddrinker (links).

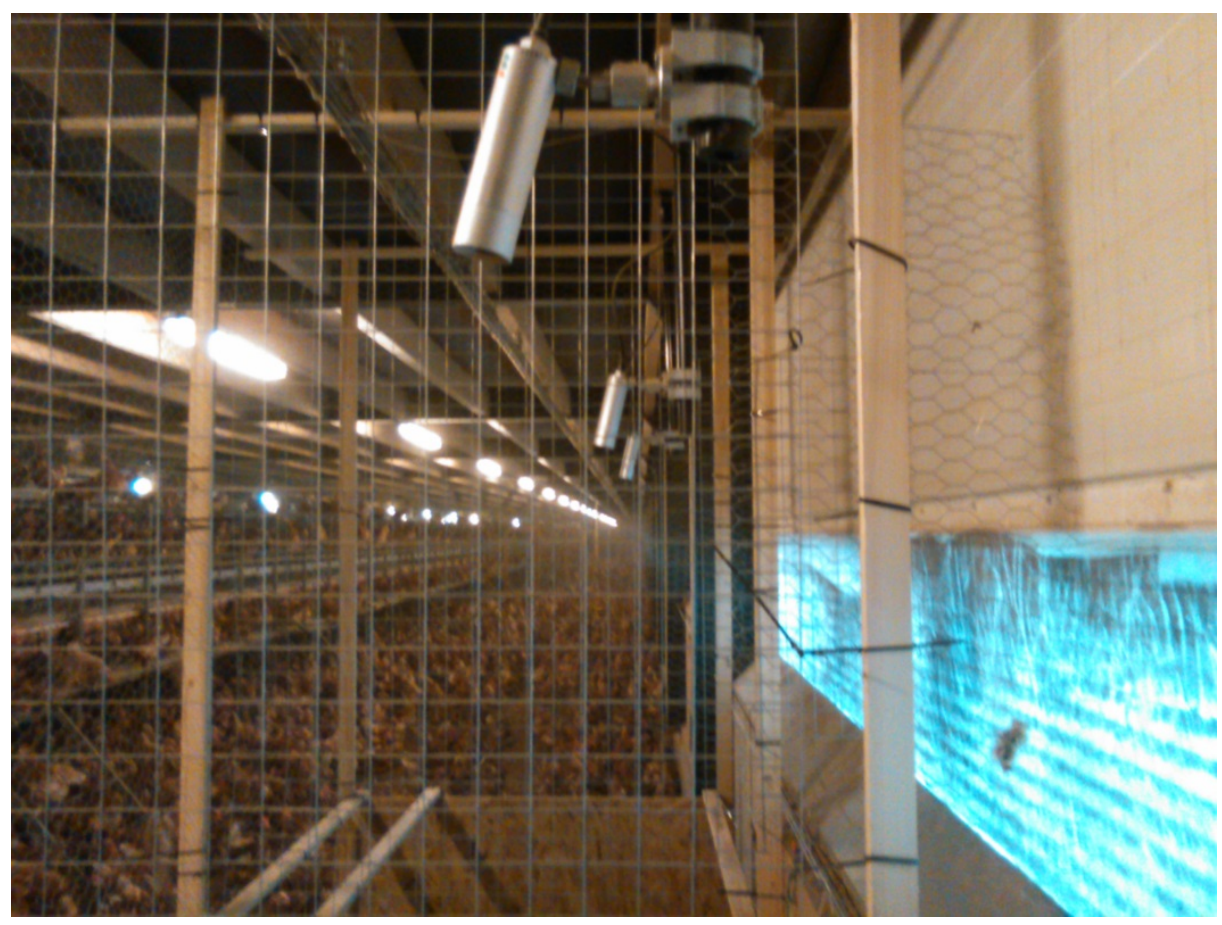

Foto 2: Camera's boven de testhokken. 

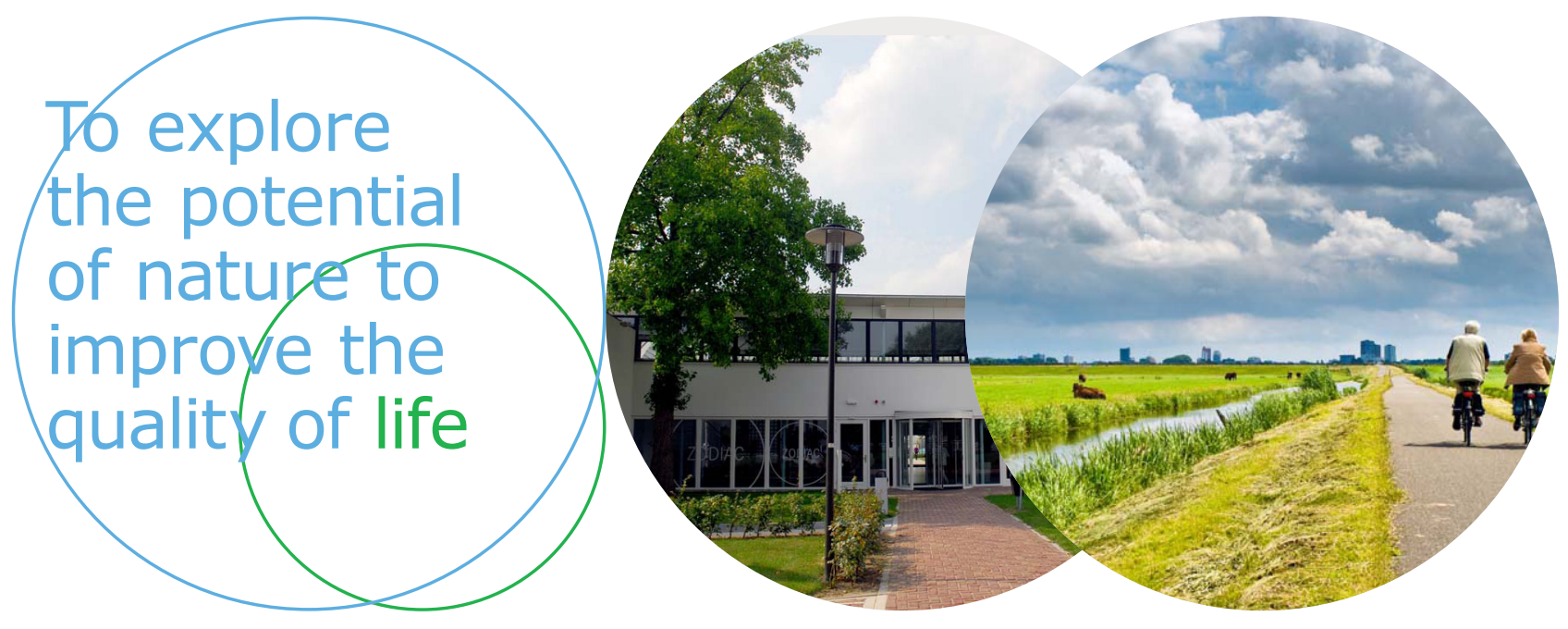

Wageningen Livestock Research Postbus 338

Wageningen Livestock Research ontwikkelt kennis voor een zorgvuldige en $6700 \mathrm{AH}$ Wageningen

T 0317483953

renderende veehouderij, vertaalt deze naar praktijkgerichte oplossingen en innovaties, en zorgt voor doorstroming van deze kennis. Onze wetenschappelijke E info.livestockresearch@wur.nl www.wur.nl/ livestock-research kennis op het gebied van veehouderijsystemen en van voeding, genetica, welzijn en milieu-impact van landbouwhuisdieren integreren we, samen met onze klanten, tot veehouderijconcepten voor de $21 \mathrm{e}$ eeuw.

De missie van Wageningen University \& Research is 'To explore the potential of nature to improve the quality of life'. Binnen Wageningen University \& Research bundelen 9 gespecialiseerde onderzoeksinstituten van Stichting Wageningen Research en Wageningen University hun krachten om bij te dragen aan de oplossing van belangrijke vragen in het domein van gezonde voeding en leefomgeving. Met ongeveer 30 vestigingen, 6.500 medewerkers en 10.000 studenten behoort Wageningen University \& Research wereldwijd tot de aansprekende kennisinstellingen binnen haar domein. De integrale benadering van de vraagstukken en de samenwerking tussen verschillende disciplines vormen het hart van de unieke Wageningen aanpak. 